\title{
Use of the Orem self-care model on pain relief in women with rheumatoid arthritis: a randomized trial
}

\author{
Elahe Sadat Saeedifar ${ }^{1}$, Robabe Memarian², Samira Fatahi ${ }^{3}$, Fatemeh Ghelichkhani ${ }^{4}$
}

${ }^{1}$ M.Sc. Student, Department of Nursing, Faculty of Medical Sciences, Tarbiat Modares University, Tehran, Iran

${ }^{2}$ Assistant Professor, Department of Nursing, Faculty of Medical Sciences, Tarbiat Modares University, Tehran, Iran

${ }^{3}$ Department of Operating Room, Kermanshah University of Medical Sciences, Kermanshah, Iran

${ }^{4}$ Department of Midwifery, Faculty of Nursing and Midwifery, Saveh University of Medical Science, Saveh, Iran

\section{Type of article: Original}

\begin{abstract}
Background and aim: Self-care is an important tool in controlling pain in patients with rheumatoid arthritis. The aim of this study was to determine the use of the Orem self-care model on pain relief in patients with rheumatoid arthritis.

Methods: This was a clinical trial performed on 60 patients with rheumatoid arthritis who referred to a rheumatology clinic in Karaj during 2013-2015 (30 patients in the control group and 30 patients in the intervention group), convenience sampling was done and subjects were divided into two groups randomly. Data collecting tools were a demographic questionnaire which consisted of 19 questions and the Numeric Pain Rating Scale. The data result was analyzed by SPSS version 19, using independent-samples t-test and Chi square test. Pvalue of less than 0.05 was considered significant.

Results: The mean age was $44.63 \pm 10.65$ years, $90 \%$ were married and $35 \%$ had a high school diploma. The results showed a significant difference in three measures of pain in the intervention group $(\mathrm{p}=0.001)$, while in the control group, this difference was not significant $(\mathrm{p}=0.59)$.

Conclusion: According to the results, the Orem self-care model is effective in reducing pain in patients with rheumatoid arthritis Therefore, applying the Orem self-care model is recommended to promote and maintain selfcare behavior in patients with rheumatoid arthritis.

Trial registration: The trial was registered at the Iran Registry of Clinical Trials (http://en.irct.ir) with code IRCT2014052517840N1.

Funding: The authors received no financial support for the research, authorship, and/or publication of this article. Keywords: Arthritis, Rheumatoid, Pain, Orem Self-Care Model, Nursing
\end{abstract}

\section{Introduction}

Rheumatoid arthritis is an autoimmune and systemic disorder that affects $2 \%$ of the adult population worldwide (1). The disease targets the age group of 35-50 years and women are 2.5 to 3 times more likely to be affected compared to men (2). The most important and widespread symptom of this disease is pain (3). Pain is the main concern of patients with rheumatoid arthritis, and therefore is the main concern of health care providers (4). Pain is the most important criterion in quality of life and is one of the determinants of disability in rheumatoid arthritis as along with self-esteem, fatigue, depression and motor limitation which are some of the outcomes of pain (5). Arthritic pain is a very complex phenomenon that has not been well investigated, and pain due to rheumatoid arthritis is the most common reason for referral to a doctor and follow-up of medical care (6). Pain, despite the impact on the patient's

\section{Corresponding author:}

Assistant Professor Dr. Robabe Memarian, Department of Nursing, Faculty of Medical Sciences, Tarbiat Modares University, Tehran, Iran.

Tel: +98.2182883554, Email: memari_r@modares.ac.ir

Received: December 30, 2017, Accepted: April 08, 2018, Published: June 2018

iThenticate screening: April 05, 2018, English editing: April 13, 2018, Quality control: April 15, 2018

This article has been reviewed / commented by four experts

Ethics approval: 52/4100-D

(C) 2018 The Authors. This is an open access article under the terms of the Creative Commons Attribution-NonCommercialNoDerivs License, which permits use and distribution in any medium, provided the original work is properly cited, the use is non-commercial and no modifications or adaptations are made. 
assessment of the condition, can also affect the physician's assessment of the health status, functional disability and the use of medications (7). Pain is a major problem for these patients, and existing pain can predict future pain and disability (8). Over the decades, researchers have identified the reduction of pain, inflammation and joint swelling as the main goal of care for these patients, and believe that achieving this goal will maximize the functional ability and social activities of these patients (9). The pain caused by rheumatoid arthritis causes physical, psychological, and economic disability, and pharmaceutical, physical and surgical interventions are often incapable of controlling pain and these patients are forced to live with this pain prolongedly (10). Medical research is involved in the study of the causes of pain reduction and control, but self-care is significantly recognized as an important tool in pain control in patients with rheumatoid arthritis (11). Assistance to patients with rheumatoid arthritis is possible through self-care improvement. (12). Empowering people experiencing chronic pain by using self-care methods is more effective than other methods (13). Patients with rheumatoid arthritis can be responsible for managing their symptoms daily in the home and for a long time, and self-care education is one of the non-medical aspects of managing the disease (14). Considering the various methods and medications used to relieve the signs and symptoms of the disease, especially pain in patients with rheumatoid arthritis, which causes side effects and costs, it is important to find a method involving the patient spending less and increasing the treatment that reduces stress and anxiety, and increasing the potential ability of the patient (15). Since the maintenance and promotion of health have been more important than treatment in recent years, the role of the nurse has also changed and there is more focus on the concept of self-care (16). The concept of self-care was first introduced by Orem. Orem believed that the patient's ability to carry out daily activities of life and establish a state of non-dependence on others depends on the nurse's skillfulness (17). According to the Orem model, when self-care is unable to provide own self-care needs of patients, we need nursing systems to maintain health. In this model, three types of care system are designed based on needs and deviations from patient health: wholly compensatory system, partly compensatory system, and supportive-educative system (18). In order to minimize the heterogeneity of self-care in rheumatoid arthritis patients, many interventions in this area should be conducted and analyzed and more attention should be given to the content of self-care programs (19). In Iran, two studies have been done on the effect of acupressure (20) and aerobic exercise (21) on pain control in RA patients, none of which were based on the pattern. Therefore, the present study was aimed to determine the effect of the Orem self-care model on the pain of patients with rheumatoid arthritis.

\section{Material and Methods}

\subsection{Trial design and participants}

This study was a randomized clinical trial that was conducted from February 2, 2013 to January 11, 2015. This clinical trial was performed on 60 women with rheumatoid arthritis who referred to the Dr. Akhyani Rheumatology Clinic in Karaj. Considering 25\% attrition for each group, 30 subjects were selected for the control group and 30 subjects for the intervention group, convenience sampling was done and subjects were divided into two groups randomly.

\subsection{Selection criteria}

The DAS28 is a measure of disease activity in rheumatoid arthritis (RA). DAS stands for 'disease activity score' and the number 28 refers to the 28 joints that are examined in this assessment. In order to match the control and intervention groups, random allocation method was used. A list of all patients with rheumatoid arthritis referred to the center who had the inclusion criteria of being female patients diagnosed with moderate severity of rheumatoid arthritis (based on DAS28 tool) according to American college rheumatology criteria, in an age group of 20 and 60 years, and having reading and writing literacy, were provided with a specified number and then using the random numbers table, the samples were randomly selected into two groups. In order to control the confounding variable, matching was used (all patients were female). It was also mentioned that women are three times more likely to suffer from RA than men, which was the reason for conducting this study on women. Figure 1 shows the summary of the selection, allocation into intervention and control groups, follow-up, and analysis of the study (CONSORT 2010 flow diagram). 


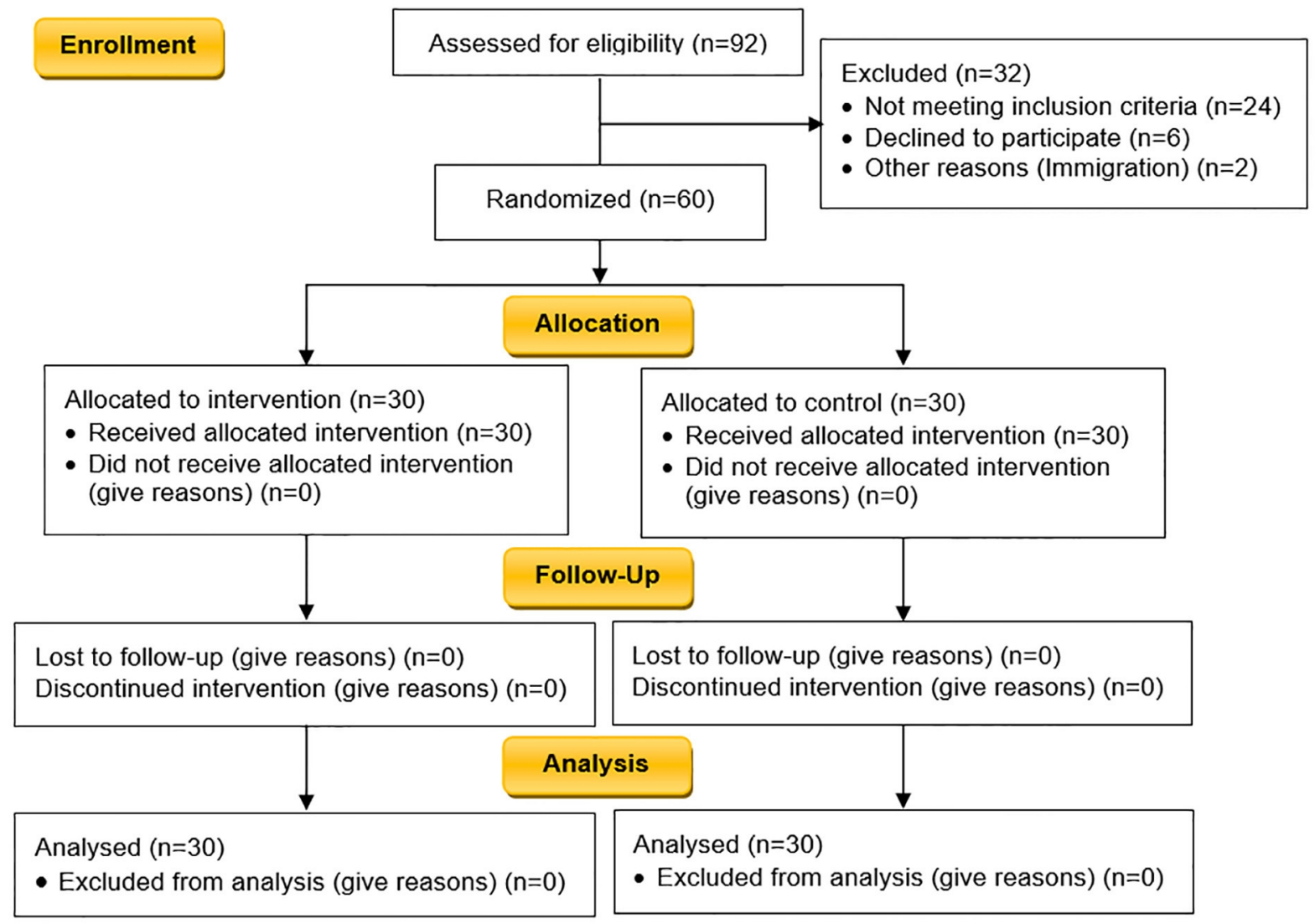

Figure 1. CONSORT 2010 Flow Diagram of the study

\subsection{Interventions and data collection}

Data collecting tools were a demographic questionnaire consisting of 19 questions and a Numeric Pain Rating Scale that was numbered from 1 to 10 , and zero was considered as non-pain, 1-3 mild pain, 4-6 intermediate pain, 7- 9 severe pain and 10 unbearable pain. The validity and reliability of this tool were internationally defined in most countries $(22,23)$. In Iran, this tool has previously been used and its validity and reliability have been measured (24). As can be seen in the ethics section of this study, the needs of patients included: self-care needs (general needs, growth and development, deviation from health), self-care capacity in the field of knowledge, attitude and skill, and reduction or defect in self-care which were studied using a form assessing self-care ability of patients with rheumatoid arthritis, and the most important needs of self-care were listed. After examining the self-care ability of patients, 19 subjects were in the support -educative system and 11 subjects in the partly compensatory system. In the planning phase, some topics were considered such as 4 sessions of theoretical and practical training for 1 to 2 hours in the field of self-care behaviors in relation to rheumatoid arthritis, joint protection methods, types of exercise, principles and correct food patterns, methods for prevention of disease recurrence, methods of pain control, strategies for stress management and progressive anxiety and progressive relaxation under the supervision of the physician, and the newest books and articles in two supportive-educative and partly compensatory systems and in accordance with the needs, studied on the basis of the Orem model in patients with rheumatoid arthritis. The number of sessions varied for each patient. In the implementation phase, some topics were considered such as mental support and encouragement of clients, guidance by providing educational pamphlets at the end of each session, follow up on self-care behaviors by telephone at intervals of each week or every two weeks and using a self-care checklist in the field of nutrition, exercise and relaxation, as well as providing a suitable home environment by participating family members in educational sessions. During this three months, the researchers were in the clinic on Monday of every week to fix possible difficulties of samples, additionally, the researcher's contact numbers were given to clients to take action if they had a problem or question. Self-care behaviors based on the Orem model were used by the intervention group for three months. However, during this period, the control group was only treated according to the current protocol by a rheumatologist. The final phase was evaluation which was conducted by interviewing and questioning the trained subjects of three months, reviewing the self-care checklist and completing 
the Orem self-care empowerment form, and the severity of pain was recorded every two weeks. The severity of pain was compared before the intervention, one month after and three months after the intervention. After the end of the study, all the training materials were delivered to the control group as a training package.

\subsection{Outcomes}

The primary outcomes of this study were information obtained from the demographic data and the severity of pain in the two groups of intervention and control. The secondary outcomes of this study were the effect of the implementation of the Orem self-care model on reducing the pain of patients with rheumatoid arthritis.

\subsection{Sample size}

The calculated sample size was 60. This sample size was calculated using Pocock's formula (25), and based on the results of previous studies (22), 22 subjects were considered, and taking into account $25 \%$ attrition for each group, 30 subjects were considered.

\subsection{Randomization and blinding}

Sampling was convenience and random sampling method was used to control the situation for the control and intervention groups. For this purpose, a list of all patients with rheumatoid arthritis referred to the clinic, which had inclusion criteria were provided with a specified number, and then using the random number table in the statistics books, in which the numbers were written, but did not follow any particular pattern, the sample was selected and randomly assigned to two groups. The randomization was done by one of the researchers who was not involved in the participants' treatment. This study was single blinded, and the participants did not know which of the two control or intervention groups they belonged.

\subsection{Statistical methods}

After collecting the data, the data were analyzed using SPSS version 19 software, descriptive and inferential statistics including independent-samples t-test for mean differences between groups, Chi square and repeated measure for mean change of numeric variables in different times. The two-tailed value of $p<0.05$ was considered as statistically significant. Also, before performing the statistical analyses, the normality of the variables' distribution was examined using the K-S test.

\subsection{Research ethics}

This research was approved by the Ethics Committee of Tarbiat Modares University of Tehran (Ref. no.: 52/4100D). In order to observe ethical issues in this study, informed written consent was obtained from all participants and they were free to continue or discontinue the study at any time and could be excluded from participation in the study without being deprived of further health care. Participants were also assured that all demographic information and their responses were kept confidential and the names of the participants in the research would only be known to the researcher and would remain confidential. For anonymity, participants could use numeric codes instead of their names. Regarding the effectiveness of Orem's self-care pattern in severity of pain, after the end of the study, all the teaching materials were delivered to the control group as a training package.

\section{Results}

The results of this study in 60 women with rheumatoid arthritis showed that the mean age of the participants was 44 years $(44.27 \pm 11.35)$ and $78.3 \%$ of them had sufficient income, $90 \%$ were married, $35 \%$ had a diploma and $40 \%$ were under diploma, $43 \%$ had more than two children and the mean duration of rheumatoid arthritis was 9.1 years. Regarding occupation, $73.3 \%$ were housewives and $18.3 \%$ were employed. CRP was positive in $60 \%$ of participants and the mean ESR was 16.5. There was no significant difference in the demographic characteristics of the two groups (Table 1). Repeated Measures showed that the mean pain in the intervention group was significantly different one month and three months after the intervention compared to before intervention $(\mathrm{p}<0.001)$. The mean pain in the control group was not significantly different one month and three months after the intervention compared to before intervention $(\mathrm{p}=0.59)$ (Table 2). 
http://www.ephysician.ir

Table 1. Comparison of demographic information of patients participating in the study.

\begin{tabular}{|c|c|c|c|c|}
\hline \multicolumn{2}{|l|}{ Variables } & $\begin{array}{l}\text { Intervention } \\
\text { group }\end{array}$ & $\begin{array}{l}\text { Control } \\
\text { group }\end{array}$ & $\begin{array}{l}\text { p-value (Chi square } \\
\text { test) }\end{array}$ \\
\hline \multirow[t]{4}{*}{ Educational level } & Elementary & $16.7(5)$ & $23.3(7)$ & \multirow[t]{4}{*}{0.085} \\
\hline & Middle school & $23.3(7)$ & $16.7(5)$ & \\
\hline & $\begin{array}{l}\text { High school } \\
\text { diploma }\end{array}$ & $40(12)$ & $33.3(10)$ & \\
\hline & College & $20(6)$ & $26.7(8)$ & \\
\hline \multirow{2}{*}{ Insurance status } & Yes & $63.33(19)$ & $73.33(22)$ & \multirow{2}{*}{0.40} \\
\hline & No & $36.66(11)$ & $26.66(8)$ & \\
\hline \multirow{3}{*}{ Marital status } & Married & $93.3(28)$ & $86.7(26)$ & \multirow[t]{3}{*}{0.69} \\
\hline & Single & $3.3(1)$ & $6.7(2)$ & \\
\hline & Widow & $3.3(1)$ & $6.7(2)$ & \\
\hline \multirow[t]{4}{*}{ Body mass index $\left(\mathrm{kg} / \mathrm{m}^{2}\right)$} & $15-18.49$ & $3.3(1)$ & 0 & \multirow[t]{4}{*}{0.72} \\
\hline & $18.5-24.9$ & $3.3(1)$ & $3.3(1)$ & \\
\hline & $25-29.9$ & $40(12)$ & $43.3(10)$ & \\
\hline & $30-35$ & $23.3(7)$ & $23.3(7)$ & \\
\hline \multirow[t]{4}{*}{ Occupation } & Housekeeper & $80(24)$ & $66.7(20)$ & \multirow[t]{4}{*}{0.53} \\
\hline & Employee & $13.3(4)$ & $23.3(7)$ & \\
\hline & Student & 0 & $3.3(1)$ & \\
\hline & Retired & $6.7(2)$ & $6.7(2)$ & \\
\hline \multirow{3}{*}{$\begin{array}{l}\text { Erythrocyte sedimentation rate } \\
\text { (ESR) }\end{array}$} & $0-19$ & $70(21)$ & $63.3(19)$ & \multirow[t]{3}{*}{0.91} \\
\hline & $20-49$ & $23.3(7)$ & $33.3(10)$ & \\
\hline & $>50$ & $6.7(2)$ & $3.3(1)$ & \\
\hline \multirow[t]{5}{*}{ Duration of the disease (year) } & $1-5$ & $30(9)$ & $23.3(7)$ & \multirow[t]{5}{*}{0.65} \\
\hline & $6-10$ & $46.7(14)$ & $43.3(13)$ & \\
\hline & $11-15$ & $6.7(2)$ & $20(6)$ & \\
\hline & $16-20$ & $13.3(4)$ & $10(3)$ & \\
\hline & $20-30$ & $3.3(1)$ & $3.3(1)$ & \\
\hline \multirow[t]{2}{*}{ C-reactive protein (CRP) } & Positive & $23.3(7)$ & $33.3(10)$ & \multirow[t]{2}{*}{0.59} \\
\hline & Negative & $6.7(2)$ & $3.3(1)$ & \\
\hline
\end{tabular}

Table 2. The mean and standard deviation of pain score in patients with rheumatoid arthritis in three measurements (before intervention, one month after and three months after intervention) between two groups.

\begin{tabular}{|l|l|l|l|}
\hline \multicolumn{2}{|l|}{ Variables } & Intervention group & Control group \\
\cline { 3 - 4 } \multicolumn{2}{|l|}{ Mean score of the pain } & Mean \pm Standard deviation & Mean \pm Standard deviation \\
\cline { 2 - 4 } & After one month & $5.00 \pm 1.53$ & $5.17 \pm 1.14$ \\
\cline { 2 - 4 } & After three months & $4.80 \pm 1.39$ & $5.10 \pm 1.12$ \\
\hline ANOVA using repeated measure & $4.03 \pm 1.37$ & $5.13 \pm 1.10$ \\
\hline
\end{tabular}

\section{Discussion}

The most important and widespread symptom of this disease is pain (3). Pain is the main concern of patients with rheumatoid arthritis and therefore is the main concern of health care providers (4). Medical research is involved in the study of the causes of pain reduction and control, but self-care is significantly recognized as an important tool in pain control in patients with rheumatoid arthritis (11). In the study of Barlow after the implementation of self-care by patients with arthritis, their ability to manage pain and other symptoms of the disease increased and the pain of patients decreased (14). In the study of Loring et al., a 6-week self-care program of arthritis was more effective than a 3-week program, and this program was effective in increasing the knowledge and control of pain in these patients (25), and another study showed that after self-care behaviors, the pain rate of patients with rheumatoid arthritis decreased by $20 \%$ (26), so were consistent with our obtained results. In the study of Warsi et al. a self-care program, which included self-management, self-care, self-efficacy, and education in patients with rheumatoid arthritis and osteoarthritis, contributed to reducing the pain and disability of these patients, which was consistent with the results of the present study (26). Miaskowski et al. also concluded that the application of psychological intervention, 
including nursing coaching within the framework of self-care, could improve the pain of the disease (27). The study of Cherkin et al. showed that after the implementation of the arthritis self-management program, patients' ability to manage pain and other symptoms such as fatigue increased and their pain was reduced, which was consistent with the results of the present study (28). Warsi et al., in another study, also showed that among 71 interventional studies (review articles) on the impact of self-care education in chronic patients, self-care education had a main role in reducing the symptoms of chronic diseases, especially pain (34) and Shariff et al. also declared that self-care can control the chronic pain of rheumatoid arthritis and create a positive sense of well-being (11). In the study of Cherkin that compared Chinese acupuncture and massage therapies and self-care education in patients with chronic lumbar pain, the results showed that self-care education, more than acupuncture and massage, had a role in controlling symptoms and reducing their pain. (28). However, in the study of Sherman et al, a randomized trial of yoga, stretching, and self-care for chronic back pain, showed that yoga and stretching were more effective than the self-care booklet in reducing pain and other symptoms of these patients (29). Fitzcharles revealed that patients with rheumatoid arthritis are more likely to be afraid of side effects of drugs, fear of drug addiction, fear of drug interactions, fear of concealment, and aversion to overdose, therefore refrain from taking the drug to control their pain, and most patients considered fear of side effects as the most important barrier to not taking medication (30). Behbahani et al. also concluded that self-care and acupressure training was more effective in reducing dysmenorrhea pain than ibuprofen tablets (31). Therefore, in order to reduce pain and other symptoms, and as a result of improving the quality of life of these patients, non-pharmacological methods should be used. One of these methods is self-care education because the self-care concept is very important for health promotion. Nursing strategies are practical guides for nurses and one of the most widely used is the self-care Orem model and the use of the Orem model in a variety of conditions such as rheumatoid arthritis can be very suitable (32). Obviously, self-care has a positive effect on patients' autonomy and it can empower patients with rheumatoid arthritis to have better control on their disease complications, and it also affects patients firmly in their care and helps them to choose and make decisions, since most patients prefer their strategies more than their doctor's advice and guidance to manage their chronic illness. But what should be considered is the nature of the program, which is based on the needs of the patient, as this model increases the motivation and desire of the patient and family and makes them more capable. The present study also showed that the implementation of a self-care Orem model based on the educational needs of patients was significantly effective in reducing their pain. One of main limitations in this study was the individual differences among studied units in terms of response to questionnaires, education of learned topics, and the application and continuation of self-care, which was not controllable.

\section{Conclusions}

The results showed that the Orem model could play an effective role in reducing the pain of patients with rheumatoid arthritis. The usefulness of the findings is that, since this model is designed to suit the needs of patients and has the greatest involvement of the patient, as well as the transfer of responsibility to family members in specific cases, it is suggested that it can also be used in other chronic diseases. A complementary research on the application of other nursing patterns to patients with rheumatoid arthritis with a clinical trial can be a good route for further research on this topic.

\section{Acknowledgments:}

This study was extracted from master's thesis of nursing from Tarbiat Modares University. The researcher would like to thank the authorities and the patients who agreed to participate and had enough patience in this research, and all those who had helped in the various stages of the research.

\section{Trial Registration:}

The trial was registered at the Iranian Registry of Clinical Trials (http://www.irct.ir) with the Irct ID: IRCT2014052517840N1.

\section{Funding:}

The authors received no financial support for the research, authorship, and/or publication of this article.

\section{Conflict of Interest:}

There is no conflict of interest to be declared.

\section{Authors' contributions:}

All authors contributed to this project and article equally. All authors read and approved the final manuscript. 


\section{References:}

1) Lapčević M, Vuković M, Gvozdenović BS, Mioljević V, Marjanović S. Socioeconomic and therapy factor influence on self-reported fatigue, anxiety and depression in rheumatoid arthritis patients. Revista brasileira de reumatologia. 2017; 57(6): 545-56. doi: 10.1016/j.rbre.2017.02.004

2) Bakker M, Jacobs J, Verstappen S, Bijlsma J. Tight control in the treatment of rheumatoid arthritis: efficacy and feasibility. Annals of the rheumatic diseases. 2007; 66(suppl 3): iii56-iii60. doi: 10.1136/ard.2007.078360.

3) Fauci AS, Langford C. Harrison's rheumatology. McGraw Hill Professional; 2010.

4) Keefe FJ, Brown GK, Wallston KA, Caldwell DS. Coping with rheumatoid arthritis pain: catastrophizing as a maladaptive strategy. Pain. 1989; 37(1): 51-6. PMID: 2726278.

5) Uutela T, Hakala M, Kautiainen H. Validity of the Nottingham Health Profile in a Finnish out - patient population with rheumatoid arthritis. Rheumatol. 2003; 42(7): 841-5. doi: 10.1093/rheumatology/keg229. PMID: 12759465.

6) Anderson DL. Development of an instrument to measure pain in rheumatoid arthritis: Rheumatoid Arthritis Pain Scale (RAPS). Arthritis Care \& Research. 2001; 45(4): 317-23. PMID: 11501718.

7) Nadriyan H, Morowatisharifabad M, Mirzaee A, Bahmanpour K, Moradzade R, Shariati M. The relationship between quality of life, health care behavior in patients with rheumatoid arthritis in Yazd. University of Medical Sciences Elam. 2011; 19(2): 15-25.

8) Van Lankveld W, Naring G, Vander staak C, Bosh P, van de Putte. Stress caused by Rheumatoid arthritis: Relation among subjective stressors of the disease, disease status, and well-Bing. Behav Med. 1993; 16(3): 309-21. doi: 10.1007/BF00844762.

9) Mendelson A, McCullough C, Chan A. Integrating self-management and exercise for people living with arthritis. Health Educ. 2011; 26(1): 167-77. doi: 10.1093/her/cyq077.

10) Roy M. living with chronic pain of rheumatoid arthritis. University of Alberta: Cana; 1997.

11) Shariff F, Carter J, Dow C, Polley M, Salinas M, Ridge D. Mind and body management strategies for chronic pain \& rheumatoid arthritis: strategies in search of wellbeing. Qual Health Res. 2009; 19(8): 103749. doi: 10.1177/1049732309341189. PMID: 19638598.

12) Taal E, Rasker JJ, Wiegman O. Patient education and self-management in the rheumatic Diseases: A selfefficacy approach. Arthritis Care Res. 1996; 9(3): 229-38. doi: 10.1002/1529-0131(199606)9:3<229::AIDANR1790090312>3.0.CO;2-U.

13) Barlow JH, Williams B, Wright CC. Instilling the strength to fight the pain and get on with life': learning to become an arthritis self-manager through an adult education programme. Health Education Research. 1999; 14(4): 533-44. doi: 10.1093/her/14.4.533. PMID: 10557523.

14) Vadiee.M. The UK Expert patient peogram and self-care in chronic disease management: An Analysis. Eur Geriatr Med. 2012; 3(3): 201-5. doi: 10.1007/s11764-007-0040-z.

15) Newman S, Mulligan K, Steed L. What is meant by self - management and how can its efficacy be established? Rheumatology. 2001; 40(1): 1-4. doi: 10.1093/rheumatology/40.1.1. PMID: 11157134.

16) Ovayolu OU, Ovayolu N, Karadag G. The relationship between self - care agency, disability levels and factors regarding these situations among patients with rheumatoid arthritis. Journal of clinical nursing. 2012; $21(1$ - 2): 101-10. doi: 10.1111/j.1365-2702.2011.03710.x.

17) Habibzadeh H, Ghofranipour F, Ahmadi F. The Effect Of Self-Care Planning On The Daily Activities Of Patients With Cerebro-Vascular Accident (Hospitalized At The Selected Urumia Hospital) Daneshvar Medicine. 2007.

18) Mahmoudzadeh-Zarandi F, Hamedanizadeh F, Ebadi A, Raiesifar A. The effectiveness of Orem's self-care program on headache-related disability in migraine patients. Iranian Journal of Neurology. 2016; 15(4): 240-7. PMID: 28435636, PMCID: PMC5392201.

19) Baker LK, Denyes MJ. Predictors of self-care in adolescents with cystic fibrosis: A test of Orem's theories of self-care and self-care deficit. Journal of Pediatric Nursing: Nursing Care of Children and Families. 2008; 23(1): 37-48. doi: 10.1016/j.pedn.2007.07.008.

20) Karimipur F, Fayazi S, Mowla K, Latifi SM. Effect of Acupressure on Severity of Pain in Arthritis Rheumatoid Patient. Jundishapur Sci Med J. 2012; 11(2): 269-75.

21) Kalali Jouneghani N, Rahnama N, Bambaeichi F, Jafari Y, Riyahi Z. The effect of eight weeks of aerobic exercise on quality of life and pain in patients with rheumatoid arthritis. JRRS. 2011; 7(3): 399-407.

22) Kessler R, Paterson D, Dane J. Hypnosis and relaxation with pain patient: Evidence for effectiveness. Pain. 2004; 1(2): 67-78. 
23) Hjermstad MJ, Fayers PM, Haugen DF, Caraceni A, Hanks GW, Loge JH, et al. Studies comparing Numerical Rating Scales, Verbal Rating Scales, and Visual Analogue Scales for assessment of pain intensity in adults: a systematic literature review. Journal of pain and symptom management. 2011; 41(6): 1073-93. doi: 10.1016/j.jpainsymman.2010.08.016.

24) Babashahi Kohanestani F, Ahmadi F, Memarian R. The Effect Of Lavender Aromatherapy Program On The Pain Intensity Of Patients With Aml Undergoing Chemotherapy. The Journal of Urmia Nursing and Midwifery Faculty. 2013; 11(3): 180-6.

25) Pocock SJ. Clinical trial, a practical approach. In: publishing JWS, editor. NewYork; 1990: 834.

26) Barlow JH, Williams B, Wright CC. Instilling the strength to fight the pain and get on with life: learning to become an arthritis self-manager through an adult education programme. Health Educ Res. 1999; 14(4): 533-44. doi: 10.1093/her/14.4.533. PMID: 10557523.

27) Loring K, Gonzalez V, Lsurent D, Morgan L. Arthritis self-management program variations: Three studies. Arthritis Rheum. 1998; 11(6): 448-54. doi: 10.1002/art.1790110604.

28) Warsi A, Valley M, Wang P, Avorn J, Solomon H. Arthritis Self-Management Education Programs: A meta-analysis of the effect on pain and disability. Arthritis Rheum. 2003; 48(8):2207-13. doi: 10.1002/art.11210

29) Miaskowski C, Dodd M, West C, Schumacher K. Randomized Clinical Trial of the Effectiveness of a SelfCare Intervention to Improve Cancer Pain Management. Nat Rev Clin Oncol. 2004; 22(9): 1713-20. doi: 10.1200/JCO.2004.06.140. PMID: 15117994.

30) Cherkin D, Eisenberg D, Sherman K, Barlow W, Kaptchuk T, Street J, et al. Randomized Trial Comparing Traditional Chinese Medical Acupuncture, Therapeutic Massage, and Self-care Education for Chronic Low Back Pain. Arch Intern Med. 2001; 161(8): 1081-8. PMID: 11322842.

31) Behbahani BM, Ansaripour L, Akbarzadeh M, Zare N, Hadianfard MJ. Comparison of the effects of acupressure and self-care behaviors training on the intensity of primary dysmenorrhea based on McGill pain questionnaire among Shiraz University students. J Res Med Sci. 2016; 21: 104. doi: 10.4103/17351995.193176. PMID: 28250781, PMCID: PMC5322691.

32) Sherman KJ, Cherkin DC, Wellman RD, Cook AJ, Hawkes RJ, Delaney K, et al. A randomized trial comparing yoga, stretching, and a self-care book for chronic low back pain. Archives of internal medicine. 2011; 171(22): 2019-26. doi: 10.1001/archinternmed.2011.524.

33) Kiely PD, Nikiphorou E. Management of rheumatoid arthritis. Medicine. 2018; 46 (4):216-21. doi: 10.1016/j.mpmed.2018.01.006.

34) Fitzcharles MA, DaCosta D, Ware MA, Shir Y. Patient Barriers to Pain Management May Contribute to Poor Pain Control in Rheumatoid Arthritis. Pain. 2009; 10(3): 300-5. doi: 10.1016/j.jpain.2008.09.012. PMID: 19070549.

35) Eccleston C, Crombez G. Worry and chronic pain: A misdirected problem solving model. Pain. 2007; 132(3): 233-6. doi: 10.1016/j.pain.2007.09.014. PMID: 17961924.

36) Minnock P, McKee G, Kelly A, Carter SC, Menzies V, O’Sullivan D, et al. Nursing sensitive outcomes in patients with rheumatoid arthritis: A systematic literature review. Int J Nurs Stud. 2018; 77: 115-29. doi: 10.1016/j.ijnurstu.2017.09.005. PMID: 29080437.

37) Simmons L. Dorthea Orem's self care theory as related to nursing practice in hemodialysis. Nephrology Nursing Journal. 2009; 36(4): 419-21. PMID: 19715109. 